\title{
EFFECT OF OBESTATIN ON PITUITARY GONADAL AXIS, LEPTIN AND MDA LEVELS IN OBESE SPRAGUE DAWLEY RATS
}

\author{
Nadia Latif, Amina Rasul*, Sajid Ali, Rimsha Zia \\ Army Medical Collage/National University of Medical Sciences (NUMS) Rawalpindi Pakistan, *Wateem Medical Collage Islamabad Pakistan
}

\begin{abstract}
Objective: To determine the effect of obestatin administration on FSH, LH, testosterone, leptin and MDA levels in obese Sprague Dawley Rats.

Study Design: Laboratory based animal study.

Place and Duration of Study: Physiology department, Army Medical College Rawalpindi, from Mar to Jun 2015.

Methodology: This randomized controlled trial was conducted at Physiology Department Army medical college. Male healthy Sprague Dawley rats were randomly divided into 3 groups (n-15 each) i.e. control group (group I) fed with normal pellet diet (NPD), obese group (group II) and obestatin treated obese group (group III) fed with high fat diet (HFD). After 10 weeks, group III was treated with obestatin $(1 \mathrm{nmol} / 100 \mathrm{ml}$ intraperitoneally). Blood samples were obtained by terminal intracardiac sampling for bioasssays of FSH, LH, testosterone, leptin and MDA by ELISA.

Results: Obestatin supplementation in obese rats showed significant increase in LH levels $(3.79 \pm 0.05)$ and testosterone levels $(2.07 \pm 0.22)$ when compared to the non treated obese rats $(2.19 \pm 0.07)$ and $(1.37 \pm 0.15)$ respectively while significant decrease in leptin $(3.85 \pm 0.23)$ and MDA levels $(1.62 \pm 0.07)$ was observed when compared to the non-treated control groups $(6.10 \pm 1.18)$ and $(1.95 \pm 0.07)$ respectively. However, serum FSH levels remained unchanged among the treated and nontreated groups.

Conclusion: Obestatin increases the testosterone levels by augmenting the pituitary gonadal axis through decrease in the oxidative stress and leptin levels in obese rats.
\end{abstract}

Keywords: Leptin, Obestatin, Obesity, Testosterone.

This is an Open Access article distributed under the terms of the Creative Commons Attribution License (https://creativecommons.org/licenses/by-nc/4.0/), which permits unrestricted use, distribution, and reproduction in any medium, provided the original work is properly cited.

\section{INTRODUCTION}

Insulin plays a vital role in regulation of hypothalamo-pituitary-gonadal axis by stimulating the release of GnRH from hypothalamus and subsequently increases LH secretion from pituitary which in turn causes increased testosterone secretion from Leydig cells. The decreased insulin responsiveness of $\mathrm{GnRH}$ neurons due to insulin resistant state consequently results in decreased testosterone output from Leydig cells secondary to the decreased level of pituitary gonadotropins ${ }^{1}$.

Male obesity has been associated with raised estrogen level subsequently causes direct inhibition of hypo-thalamo-pituitary-gonadal axis causing further reduction in serum testosterone levels ${ }^{2}$. Visceral obesity is a proinflammatory state associated with increased production of inflammatory cytokines like IL-6 and TNF a by adipocytes. Both IL- 6 and TNF are documented to activate hypothalamo-pituitary-adrenal (HPA) axis to increase glucocorticoid secretion and cause further visceral obesity which further enhances hypersecretion of these inflammatory cytokines and attenuation of hypothalamo-pituitary-gonadal (HPG) axis ${ }^{3}$.

Correspondence: Dr Nadia Latif, Department of Physiology, Army Medical College, Rawalpindi Pakistan

Received: 21 Apr 2021; revised received: 16 Jun 2021; accepted: 23 Jun 2021
Adipocytes cause increased production of adipocytokines including adiponectin and leptin. These are documented to act in paracrine and endocrine fashion to modulate reproduction and fertility both in health and disease states. The increased leptin level is documented to cause direct inhibition of testosterone secretion by Leydig cells. Leptin is documented to act as positive regulator of reproduc-tive hormonal axis through modulation of kisspeptin neurons present in Arcuate nucleus 4 . The direct action of leptin on anterior pituitary is known to increase LH and to a lesser extent FSH secretion via nitric oxide synthetase pathway ${ }^{5}$. Elevated leptin levels have been documented to inhibit testosterone secretion by acting directly on the Leydig cells and influencing the underlying molecular mechanism of testicular steroidogenesis including the decreased expression of mRNA encoding steroidogenic factor-1, steroidogenic acute regulatory protein (StAR) and cytochrome P450 cholesterol side chain cleavage enzymes. These proteins play a pivotal role in testosterone biosynthesis in Leydig cells and mark the rate limiting steps in testosterone biosynthesis ${ }^{4}$.

Obestatin is derived from 117 amino acid peptide preproghrelin which is encoded by ghrelin gene. Obestatin level has been documented to decrease in obesity and increase in patients with anorexia nervosa ${ }^{6}$. It has 
been documented that obestatin counters the obesity by decreasing the food intake. It also modulates adipocyte differentiation by augmenting adipogenesis 7 . The plasma levels of obestatin are found to be negatively correlated with leptin in obesity which manifests its role as a novel regulator of glucose metabolism and adipocyte function ${ }^{8}$. Obestatin increases the testosterone secretion from the interstitial Leydig cells of rat testis in vitro as well as in vivo after chronic intraperitoneal administration. Chronic supplementation of obestatin in male rats has shown to stimulate the proliferation of testicular cells in seminiferous tubules. The obestatin is believed to induce testosterone secretion dose dependently after its intravenous administration. The mechanism is not yet known however it has been suggested that modulation of testicular function by obestatin may be either due to its direct action on testes through G-protein-related orphan receptor 39 (GPR39) or due to the increased responsiveness of Leydig cells to the circulating LH levels or modulation of GnRH levels9.

The possible mechanism of modulation of testicular function by obestatin has not yet been elucidated. Therefore, present study was designed to evaluate the beneficial effect of obestatin on serum testosterone by modulating FSH, LH or oxidative stress and leptin levels in obese Sprague Dawley rats.

\section{METHODOLOGY}

The study was conducted primarily in Army medical college in department of Physiology after obtaining formal approval from ethics review committee (ERC/ID/116) of the institute. To conduct this randomized controlled trial, 45 male Sprague Dawley rats were procured from National Institute of health Sciences (NIH), Islamabad, from Mar to Jun 2015. The rats weighing 250-300 gms were procured from the animal house of NIH and divided into three groups with 15 rats in each group. All groups were kept under ambient conditions with temperature of $24-26^{\circ} \mathrm{C}$ and a $12-$ hourly photo period of day and night daily.

Group I (control group n=15) were given normal pellet diet (NPD) ad libitum was given for 3 weeks and were subjected to overnight fast for 12 hours followed by tail vein sampling. $2 \mathrm{~mL}$ blood was drawn and later utilized for blood glucose and serum insulin for determination of insulin resistance by Homeostatic Model assessment for insulin(HOMA-IR). NPD was continued to this group of rats for next 8 weeks after which daily IP injections of normal saline $(100 \mathrm{uL})$ were administered for 10 days.
Group II (Obese group n=15) were given high fat diet (HFD) for 3 weeks followed by an overnight fast for 12 hours. Tail vein sampling was then conducted to draw $2 \mathrm{ml}$ of blood. The sample was utilized to assess the blood glucose and serum insulin for HOMA-IR determination. HFD was continued to be given to the rats for next 8 weeks after which the blood glucose of each rat was measured to ensure that the fasting level remained $<200 \mathrm{mg} / \mathrm{dl}$ for exclusion of diabetic rats from the group. After the blood glucose measurement, daily IP injections of normal saline (100uL) were administered for 10 days.

Group III (obestatin group $\mathrm{n}=15$ ) were treated in the similar manner as group II. At end of the study, intra peritoneal injections of obestatin in the dose of $1 \mathrm{ml} / 100 \mathrm{uL}$ were administered for 10 days.

At the end of 13 weeks, the rats were euthanized with overdose of ether anesthesia. Intra cardiac puncture was done to obtain the terminal blood sample (4$5 \mathrm{ml})$ and collected in serum gel separate tubes. Serum was obtained by cold centrifugation of the sample and stored at $-80 \mathrm{oC}$ for measurement of serum insulin, testosterone, FSH, LH, leptin and MDA by enzyme-linked immunosorbent assay (ELISA).

Data was analyzed on SPSS version 21. Mean \pm $\mathrm{SD}$ was determined for quantitative variables. Analysis of variance (ANOVA) was applied to determine difference among the groups. This was followed by Posthoc Tukey test for inter-group comparison and determination of $p$-value. The $p$-value of $<0.05$ was considered significant.

\section{RESULTS}

The study was conducted in an animal model comprised of a total number of 45 healthy, obese male Sprague Dawley rats to evaluate the effect of obestatin on serum testosterone by modulating FSH, LH, MDA and leptin levels. Mean weight of rats inducted at the time of study was $256 \pm 5.56 \mathrm{~g}$ while their plasma glucose level was $88.13 \pm 5.95 \mathrm{mg} / \mathrm{dl}$. Both of the parameters were well within normal range.

The comparison of FSH, LH, testosterone, leptin and levels between control, obese and obestatin treated obese groups by one-way ANOVA (table-I) revealed that all the hormone levels were different amongst three groups. The comparison of two groups by Post hoc Tukey's HSD revealed that FSH ( $p$-value $=0.04)$, LH $(p$-value $=0.038)$ and testosterone $(p$-value $=0.04)$ levels of the obese were significantly lower than non-treated healthy rats. FSH ( $p$-value $=0.013), \mathrm{LH}(p$-value $=0.01)$ 
and testosterone levels ( $p$-value $=0.01)$ of obestatin treated obese groups were significantly higher than the non-treated obese. On comparison of group I and III, the levels of FSH ( $p$-value $=0.049)$, LH $(p$-value $=0.05)$ and testosterone $(p$-value $=0.03)$ were significantly decreased in group III (table-II).
Our data revealed that obestatin treatment resulted in significant decrease in MDA levels of obese rats when compared to non-treated obese group. Intraperitoneal administration of obestatin for 10 days has been documented to decrease lipid peroxidation by decreasing tissue and serum MDA levels in dextran sulfate

Table-I: Comparison of FSH, LH, testosterone leptin levels and MDA levels between control, obese and obestatin treated obese groups by one way ANOVA at the end of study.

\begin{tabular}{|c|c|c|c|c|}
\hline Parameters & $\begin{array}{l}\text { Group-I (Control) } \\
\qquad(\mathrm{n}=15)\end{array}$ & $\begin{array}{l}\text { Group II (Obese) } \\
\qquad(\mathrm{n}=15)\end{array}$ & $\begin{array}{c}\text { Group III } \\
\text { (Obestatin Treated } \\
\text { Obese) }(n=15)\end{array}$ & ${ }^{*} p$-value \\
\hline Serum FSH (ng/ml) & $11.74 \pm 0.14$ & $9.02 \pm 0.12$ & $10.59 \pm 0.29$ & 0.035 \\
\hline Serum LH (ng/ml) & $4.17 \pm 0.86$ & $2.19 \pm 0.07$ & $3.79 \pm 0.05$ & 0.043 \\
\hline Serum testosterone $(\mathrm{ng} / \mathrm{ml})$ & $2.36 \pm 0.10$ & $1.37 \pm 0.15$ & $2.07 \pm 0.22$ & 0.039 \\
\hline Serum leptin $(\mathrm{ng} / \mathrm{ml})$ & $2.81 \pm 0.33$ & $6.10 \pm 1.18$ & $3.85 \pm 0.23$ & 0.016 \\
\hline Serum MDA (ng/ml) & $1.44 \pm 0.05$ & $1.95 \pm 0.07$ & $1.62 \pm 0.07$ & 0.012 \\
\hline
\end{tabular}

Table-II: Comparison of FSH, LH, testosterone, leptin and MDA levels between two groups of control, obese and obestatin treated obese rats by post hoc Tukey's HSD test at the end of the study.

\begin{tabular}{c|c|c|c|c|c}
\hline $\begin{array}{c}\text { Group } \\
\text { comparison }\end{array}$ & Serum FSH & Serum LH & Serum testosterone & Serum leptin & Serum MDA \\
\hline I Vs II & 0.04 & 0.038 & 0.04 & 0.008 & 0.024 \\
\hline I Vs III & 0.049 & 0.05 & 0.03 & 0.03 & 0.042 \\
\hline II Vs III & 0.013 & 0.01 & 0.01 & 0.028 & 0.034 \\
\hline
\end{tabular}

The comparison of leptin and MDA levels between the control healthy group and non-treated obese revealed significantly higher levels in the control group however the levels of leptin and MDA levels were significantly lower in the obese group when compared to the treated obese rats as presented in table-II. The comparison of Leptin and MDA levels among the healthy and treated group reveled significantly lower level in the treated group.

\section{DISCUSSION}

Obesity and T2DM are recognized as chronic metabolic disorders adversely affecting nearly all systems of the body. In this regard, the incidence of obesity induced infertility has been documented to increase in men. In our study, MDA levels were measured as a marker of oxidative stress which had been documented to indicate lipid peroxidation. The non-treated obese rats manifested increased MDA levels when compared to healthy rats at the end of study indicating the development of profound oxidative stress due to chronic intake of HFD. This finding is in accordance with the observations documented by Xaio et al (2020) that the high cholesterol diet induced obesity in male mice resulted in increased MDA levels in obese group when compared to lean rats. The ROS act on the lipid membranes and cause excessive lipid peroxidation resulting in increased levels of $\mathrm{MDA}^{10}$. sodium induced colitis in Sprague Dawley (SD) rats ${ }^{11}$. The decrease in MDA levels might be due to the antioxidant effects of obestatin and its ability to restore oxidative balance or by increasing adiponectin levels which combat the accumulation of reactive oxygen species (ROS) by acting as an antioxidant agent ${ }^{12}$. It is evident that intraperitoneal administration of obestatin decreases lipid peroxidation in these studies and is comparable to ours.

In our experimental model, induction of obesity resulted in elevated leptin levels in obese groups when compared to their healthy counterparts. In our study, HFD induced body weight gain in obese rats resulted in increased stores of body fat enhanced the leptin levels in these groups. This finding is in agreement with observations documented by Leibowitz et al, (2004) where rats fed diet consisting of $50 \%$ fat content manifested elevated levels of leptin, insulin, triglycerides and blood glucose ${ }^{13}$. A study conducted by Virginia et al. Clements (2018) revealed that elevated leptin and insulin levels were found in HFD (45\% animal fat) fed mice. It was observed that the cumulative leptin secretion was increased as a result of increased pulse amplitude of leptin secretion from adipocytes of white adipose tissue due to high fat feeding ${ }^{14}$.

In this study, the obese rats showed significantly decreased levels of FSH, LH and testosterone when 
compared to the healthy group. This decrease in pituitary gonadotropins in obesity has been attributed to excessive aromatization of testosterone into estrogen in white adipose tissues. This leads to elevation in estrogen levels which in turn directly inhibits the hypothalamo-pituitary axis resulting in decreased LH and FSH secretion from anterior pituitary ${ }^{15}$.

Insulin resistance has closely been linked to serum testosterone concentration. Under normal physiological conditions, insulin enhances Leydig cell steroid ogenesis by its action on insulin receptors, however in insulin resistant states such as obesity and T2DM, this stimulatory action is lost due to target organ resistance culminating in impaired Leydig cell steroidogenesis ${ }^{16}$.

Under normal physiological conditions, leptin is responsible for induction of fertile state by indirectly increasing the GnRH levels consequently increasing $\mathrm{LH}$ and FSH concentrations. High fat diet intake for more than 8 weeks results in the development of leptin resistance which blunts the response of hypothalamopituitary gonadal axis to normal leptin levels. Leptin receptors have been documented to be present on Leydig cells, and in vitro studies have demonstrated that leptin directly inhibits hCG stimulated testosterone secretion from rat Leydig cells at concentrations similar to the levels found in obese men. Elevation of serum leptin levels have been documented to adversely affect testicular steroidogenesis culminating in decreased testosterone output from the Leydig cells. Elevated leptin levels had been documented to act directly on testes causing decreased testosterone output by perturbing mitochondrial function ${ }^{17}$. The decrease in $\mathrm{FSH}, \mathrm{LH}$ and testosterone in obese and rats in our study can be attributed to the development of leptin resistance causing fall in pituitary gonadotropins. However, the decline in testosterone levels might the result of direct inhibition of testicular steroidogenesis by elevated leptin levels in these groups. The mechanisms linked to reduction in pituitary gonadotropins and testosterone secretion in obese rats could be due to an increase in HOMA-IR, elevated leptin levels and increased oxidative stress depicted by the raised MDA levels.

In this study, the obestatin treatment of obese group revealed significantly decreased leptin levels when compared to their non-treated groups. Obestatin and leptin concentration levels have been negatively correlated in obesity. In HFD fed mice, obestatin is documented to reduce leptin and increased adiponectin secretion from adipocytes along with simultaneous decline in the insulin resistance by enhancing AMPK activation. This effect of obestatin is coupled with inhibition of lipolysis and enhanced adipogenesis in white adipose tissue. In a number of studies obestatin failed to modulate leptin levels ${ }^{18,19}$. The reason for this discrepancy might be due to the difference in mode of administration and varied dose of obestatin in these studies.

The data of our study showed an elevation in FSH, LH and testosterone levels in obestatin treated healthy obese rats. Anterior pituitary cells have been documented to express greater number of obestatin receptors, GPR 39. The obestatin has been observed to cause spurious permeation of blood brain barrier followed by its rapid degradation after endocytosis ${ }^{20}$. Action of obestatin might be due to stimulatory effect on GnRH neurons which anatomically are documented to lie outside the blood brain barrier ${ }^{21}$. In our study, GnRH was not measured but perhaps elevation of GnRH was responsible for rise in FSH and LH which subsequently increased the testosterone secretion by Leydig cells. The rise in testosterone secretion following obestatin administration has been reported in obestatin treated SD rats when compared to the control. This effect of obestatin on plasma testosterone has been proposed either due to binding of obestatin with its receptors on Leydig cells or increase responsiveness of Leydig cell to circulating LH levels. The obestatin has also been documented as a potent stimulator of testicular function because it causes an increase in primary and secondary spermatocytes, spermatids and Leydig cell population on testicular morphometry ${ }^{22}$. Additional mechanisms might be responsible for improvement of pituitary gonadotrophins and testosterone levels in obestatin treated obese rats in our study, which can be associated with the decrease in leptin levels that counteracts the inhibitory effect of elevated leptin on Leydig cell steroidogenesis, reduction in oxidative stress exhibited by the decline in MDA levels or through reduction in leptin resistance which can restore stimulatory role of leptin on hypothalamo-pituitary-gonadal axis.

\section{CONCLUSION}

Obestatin increases the testosterone levels by augmenting the pituitary gonadal axis through decrease in the oxidative stress and leptin levels in obese rats.

\section{CONFLICT OF INTEREST}

This study has no conflict of interest to be declared by any author. 


\section{REFERENCES}

1. Green BD, Grieve DJ. Biochemical properties and biological actions of obestatin and its relevence in type 2 diabetes. Peptides. 2018; 100(1): 249-59.

2. Bellastella G, Menafra D, Puliani G, Colao A, Savastano S. How much does obesity affect the male reproductive function. Int J Obes Suppl 2019; 9(1): 50-64.

3. Craig JR, Jenkins TG, Carrell DT, Hotaling JM. Obesity, male infertility, and the sperm epigenome. Fertil Steril 2017; 107(4): 848-59.

4. Sengupta P, Bhattacharya K, Dutta S. Leptin and male reproduction. Asian Pac J Reprod 2019; 8(5): 220-25.

5. Zhai L, Zhao J, Zhu Y, Liu Q, Niu W, Liu C, et al. Downregulation of leptin receptor and kisspeptin/GPR54 in the murine hypothalamus contributes to male hypogonadism caused by highfat diet-induced obesity. Endocrine 2018; 62(1): 195-206.

6. Orsso C, Butler A, Muehlbauer M, Cui H, Rubin D, Pakseresht $M$, et al. Obestatin and adropin in Prader Willi syndrome and nonsyndromic obesity: associations with weight, BMI-Z, and HOMA-IR. Pediatr Obes 2019; 14(5): e12493-98.

7. Irez T, Karkada IR, Dutta S, Sengupta P. Obestatin in male reproduction and infertility. Asian Pac J Reprod 2019; 8(1): 239-43.

8. Granata R, Gallo D, Luque RM, Baragli A, Scarlatti F, Grande C, et al. Obestatin regulates adipocyte function and protects against diet-induced insulin resistance and inflammation. FASEB J 2012; 26(8): 3393-11.

9. Sengupta P, Dutta S. Hormones in male reproduction and fertility. Asian Pac J Reprod 2019; 8(5): 187-88.

10. Xiao Y, Zhu Q, Liu X, Jiang M, Hao H, Zhu H, et al. High-fat diet selectively decreases bone marrow lin-/CD117+ cell population in aging mice through increased ROS production. J Tissue Eng Regen Med 2020; 14(6): 884-92.

11. Pamukcu O, Kumral ZNO, Ercan F, Yegen BÇ, Ertem D. Antiinflammatory Effect of Obestatin and Ghrelin in Dextran Sulfate Sodium-Induced Colitis in Rats. J Pediatr Gastroenterol Nutr 2013; 57(2): 211-18.

12. Allwsh TA, Mohammad JA. The Effect of Isolated Obestatin Hor- mone from Plasma on some Biochemical Parameters in Normal and Diabetic Rats. Raf J Sci 2014; 25(1): 82-100.

13. Leibowitz S, Chang GQ, Dourmashkin J, Yun R, Julien C, Pamy $P$. Leptin secretion after a high-fat meal in normal-weight rats: strong predictor of long-term body fat accrual on a high-fat diet. Am J Physiol Endocrinol Metab 2006; 290(2): E258-E67.

14. Clements VK, Long T, Long R, Figley C, Smith DM, OstrandRosenberg S. Frontline Science: High fat diet and leptin promote tumor progression by inducing myeloid-derived suppressor cells. J Leucok Biol 2018; 103(3): 395-407.

15. Kasturi SS, Tannir J, Brannigan RE. The metabolic syndrome and male infertility. J Androl 2008; 29(3): 251-29.

16. Pitteloud N, Hardin M, Dwyer AA, Valassi E, Yialamas M, Elahi $\mathrm{D}$, et al. Increasing insulin resistance is associated with a decrease in Leydig cell testosterone secretion in men. J Clin Endocrinol Metab 2005; 90(5): 2636-41.

17. Amjad S, Baig M, Zahid N, Tariq S, Rehman R. Association between leptin, obesity, hormonal interplay and male infertility. Andrologia 2019; 51(1): e13147-50.

18. Zhang JV, Ren PG, Avsian-Kretchmer O, Luo C-W, Rauch R, Klein C, et al. Obestatin, a peptide encoded by the ghrelin gene, opposes ghrelin's effects on food intake. Science 2005; 310(5750): 996-99.

19. Nogueiras R, Pfluger P, Tovar S, Arnold M, Mitchell S, Morris A, et al. Effects of obestatin on energy balance and growth hormone secretion in rodents. Endocrinol 2007; 148(1): 21-26.

20. Pan W, Tu H, Kastin AJ. Differential BBB interactions of three ingestive peptides: obestatin, ghrelin, and adiponectin. Peptides 2006; 27(4): 911-16.

21. Herde MK, Geist K, Campbell RE, Herbison AE. Gonadotropinreleasing hormone neurons extend complex highly branched dendritic trees outside the blood-brain barrier. Endocrinol 2011; 152(10): 3832-41.

22. Afsar T, Jahan S, Razak S, Almajwal A, Abulmeaty M, Wazir H, et al. Obestatin modulates ghrelin's effects on the basal and stimulated testosterone secretion by the testis of rat: an in vitro study. Physiol Res 2017; 66(1): 93-96. 